\title{
O Impacto das Características do Negócio nas Decisões Logísticas e na Organização do Fluxo de Produtos: um Estudo Exploratório em Seis Setores Econômicos
}

\author{
Peter Fernandes Wanke
}

\section{Resumo}

Este artigo tem por objetivo avaliar as relações das características do produto, da operação e da demanda com as decisões logísticas de coordenação do fluxo de produtos acabados, alocação dos estoques e base para acionamento da fabricação. Também são avaliadas as relações destas características com os tipos de organização do fluxo de produtos construídos a partir da combinação destas decisões. Uma pesquisa de campo exploratória foi conduzida nos seis maiores setores industriais listados no ranking Exame Melhores e Maiores, possibilitando a análise das correlações destas decisões com as características e o desenvolvimento de quadros conceituais de apoio à decisão. A principal conclusão da pesquisa aponta que não existe um conjunto homogêneo de características capaz de explicar as decisões tomadas, o que sugere a necessidade de segmentar uma eventual estratégia logística com base nas características do negócio.

Palavras-chaves: logística; organização do fluxo de produtos; características do negócio; estudo exploratório; empresas brasileiras.

\begin{abstract}
The main objective of this manuscript is to evaluate the relationships among the characteristics of the product, the operation and the demand and the logistics decisions regarding Push/Pull, Centralization/Decentralization and Make to Order/Make to Stock. The relationships among the combinations of these three decisions and these business characteristics are also evaluated. An exploratory study was conducted in six Brazilian major industries and correlation analyses were developed. Several conceptual frameworks to support decision-making in these two different levels are presented and discussed. The major finding of the research leads to the concept of logistics segmentation based on the business characteristics, since there is no uniform set of characteristics capable of explaining all decisions considered.
\end{abstract}

Key words: logistics; product flow; business characteristics; exploratory study; Brazilian companies. 


\section{INTRODUÇÃO}

É crescente na literatura especializada de operações e serviços a importância atribuída à logística como elemento fundamental ao gerenciamento eficiente e eficaz de cadeias de suprimentos (ver, por exemplo, Lambert, Cooper e Pagh [1998]). Por gerenciamento de cadeia de suprimentos normalmente se entende a gestão dos fluxos correlatos de produtos, de informações e de recursos financeiros que vão desde o fornecedor inicial ao consumidor final (Ballou e Gilbert, 2000). A logística tem como missão principal a minimização do custo total da operação para determinado nível de serviço e é importante processo para o gerenciamento da cadeia de suprimentos, pois viabiliza a consecução destes fluxos no espaço e no tempo (Bowersox e Closs, 1996).

Para que a logística assuma papel relevante na criação de vantagem competitiva em cadeias de suprimentos, suas principais decisões devem ser articuladas ao longo do tempo, permitindo o desenvolvimento de padrões de decisão coerentes com as características do negócio. De modo geral, o desenvolvimento de padrões de decisão coerentes com as características do negócio visa à criação e à manutenção de posições competitivas sustentáveis e é uma questão amplamente estudada pela área de estratégia empresarial.

Segundo Porter (1991), esta questão estratégica poderia ser avaliada nos níveis transversal e longitudinal. O nível transversal trataria da ligação das características do negócio (por exemplo, produto, operação e demanda) com o padrão de decisões na cadeia/sistema de valor num determinado momento do tempo. O nível transversal possibilitaria melhor desempenho em termos de custo total e de nível de serviço, por meio do ajuste fino entre as decisões e as características do negócio. O nível longitudinal examinaria por que certas empresas conseguiram desenvolver posições de vantagem competitiva e sustentá-las ao longo do tempo. O autor aponta que a avaliação do nível transversal seria prioritária, porquanto, "sem uma compreensão específica do que sustenta uma posição desejável, seria extremamente complexo lidar de forma analítica com o nível longitudinal” (Porter, 1991).

Com relação à avaliação do nível transversal, a literatura de operações e serviços registra, de forma dispersa e difusa, que determinados padrões de decisão na logística seriam mais aderentes e/ou seriam verificados com maior freqüência para determinado conjunto de características do produto, da operação e da demanda. Com o objetivo de compreender o melhor nível 
transversal na logística, foi desenvolvida uma pesquisa de campo, de caráter exploratório, em seis setores econômicos. Este estudo exploratório teve como objetivo principal identificar quais características do produto, da operação e da demanda conformam as principais decisões logísticas, em empresas fabricantes de bens de consumo, que vendem não exclusivamente, mas necessariamente, ao varejo.

Nesta pesquisa foram consideradas as seguintes decisões logísticas: coordenação do fluxo de produtos acabados (empurrar versus puxar); alocação dos estoques de produtos acabados (centralização versus descentralização); e base para acionamento da fabricação de produtos acabados (produção contra-pedido versus produção para estoque). De acordo com Leeuw e Goor (1999), mediante estas três decisões seria possível caracterizar a organização do fluxo de produtos em suas dimensões mais amplas: responsabilidade (coordenação do fluxo de produtos); espaço (alocação dos estoques) e tempo (base para acionamento da fabricação).

\section{Referencial Teórico: a Relação das Características do Negócio com as Decisões Logísticas}

Nesta seção são apresentadas as razões conceituais e as evidências empíricas encontradas na literatura sobre como e por que diferentes características do produto, da operação e da demanda favoreceriam determinados padrões de decisões logísticas e, conseqüentemente, da organização do fluxo de produtos. Deve ser lembrado que a organização do fluxo de produtos é visceralmente associada ao propósito da logística. De acordo com a definição do Council of Logistics Management - CLM (20-): "a logística é a parte do gerenciamento de cadeias de suprimento responsável pela organização, de modo eficiente e eficaz, do fluxo de produtos e de informações do ponto de origem até o ponto de consumo final”.

\section{Coordenação do Fluxo de Produtos Acabados}

A noção de puxar ou de empurrar o fluxo de produtos acabados estaria diretamente relacionada ao estágio da cadeia responsável pela decisão de ressuprimento dos estoques (Leeuw e Goor, 1999): se o estágio posterior, mais próximo do cliente ou consumidor final, ou se o estágio anterior, mais próximo do fornecedor inicial. Um fluxo de produto puxado teria seu início no estágio posterior, por meio da transmissão para o estágio anterior de informação, baseada 
na demanda real, solicitando o fornecimento. Por outro lado, um fluxo empurrado teria seu início no estágio anterior, mediante a estimativa, por técnicas de previsão ou outros métodos de planejamento, das necessidades de consumo futuras. Evidências empíricas, apontadas por diversos autores (Stalk, 1988; Inman, 1999; Christopher, 2000), indicam duas características que deveriam ser observadas nesta decisão: o prazo de entrega para o cliente final (PE) e a visibilidade da demanda (VD) ${ }^{(1)}$.

Longos prazos de entrega favoreceriam que a coordenação do fluxo de produtos fosse puxada com base na demanda real, ou seja, controlada pelo estágio mais próximo do consumidor final. Contrariamente, prazos de entrega mais curtos exigiriam que o fluxo de produtos fosse empurrado com base em previsões de venda, ou seja, controlado pelo estágio mais próximo do fornecedor inicial.

Um dos principais problemas relativos à coordenação do fluxo de produtos é a visibilidade limitada da demanda do consumidor final. O ponto até o qual a demanda do consumidor final penetra na cadeia de suprimentos em direção ao fornecedor inicial, é conhecido como ponto de desacoplamento (decoupling point), segundo Christopher (2000), ou como ponto de penetração do pedido (order penetration point), segundo Sharman (1984). O conceito implícito no ponto de desacoplamento é a mudança na forma de coordenar os fluxos de produtos. Na realidade, a questão principal não é quão distante do consumidor final está sendo colocado um pedido, mas se a demanda do consumidor final é acessível ou não para determinado estágio da cadeia. A não visibilidade desta demanda poderia levar ao planejamento empurrado por previsões de vendas, ao passo que a visibilidade desta demanda permitiria a reação com base na demanda real (Christopher, 2000).

\section{Alocação dos Estoques de Produtos Acabados}

De acordo com a literatura, diferentes características do produto, da operação e da demanda afetariam a centralização ou a descentralização dos estoques de produto acabado. As características do produto que afetariam a alocação dos estoques seriam o custo do produto vendido $(\mathrm{CPV})^{(2)}$, a densidade de custos $(\mathrm{DC})^{(3)}$ e a obsolescência $(\mathrm{O})^{(4)}$. De maneira geral, poderia afirmar-se que quanto maiores o custo do produto vendido, a densidade de custos e a obsolescência, tanto maior a tendência para centralização dos estoques (Silver e Peterson, 1985; Ballou, 1992; Christopher, 1997).

Produtos com maior custo do produto vendido e maior obsolescência tenderiam a ficar centralizados em função, respectivamente, de maiores custos de 
oportunidade de manter estoque e de maiores riscos de perdas de estoque. Já produtos com menor densidade de custos refletiriam maior necessidade para minimizar os custos unitários de distribuição, de modo a assegurar a sua competitividade em preço. A descentralização dos estoques permitiria a consolidação de carregamentos e a conseqüente diluição dos custos fixos de distribuição por maior número de produtos (Jayaraman, 1998).

Por outro lado, entre as características da demanda e da operação que influenciariam a alocação dos estoques, cabe destacar, respectivamente, o coeficiente de variação nas vendas (CV) $)^{(5)}$ e o giro dos estoques (G). Quanto menor o coeficiente de variação nas vendas e maior o giro dos estoques, tanto maior a propensão para descentralização dos estoques, basicamente porque são minimizados os riscos associados ao encalhe dos produtos (Silver e Peterson, 1985; Waters, 1992; Mentzer, Kahn e Bienstock, 1998).

\section{Base para Acionamento da Fabricação de Produtos Acabados}

Envolveria a decisão entre produzir para estoque ou contrapedido, sendo sua integração com a decisão de alocação dos estoques de produto acabado de fundamental importância para o desenho dos sistemas logísticos (Bowersox e Closs, 1996; Closs e Roath, 1998; Pagh e Cooper, 1998). Algumas características do produto e da operação que influenciariam esta decisão seriam o custo do produto vendido, a obsolescência e a razão entre prazos (RP) ${ }^{(6)}$.

O custo do produto vendido pode ser interpretado como o volume de capital de giro necessário para produzir uma unidade adicional (Lambert, Cooper e Pagh, 1998). Quanto maior o custo do produto vendido, tanto maior seria a propensão para produzir contrapedido. Analogamente, quanto maior a obsolescência, maior a propensão para produzir contrapedido, a fim de evitar perdas dos estoques (Abad, 2003). Finalmente, quanto maior a razão entre prazos, maior o prazo de entrega dos produtos para o cliente, em comparação ao prazo de entrega das matérias primas pelo fornecedor. Esta diferença de prazos poderia favorecer a produção contrapedido, na medida em que haveria maior janela para a acomodação do tempo de resposta da produção, observando-se os limites do ciclo do pedido (Romero, 1991; Inman, 1999).

Tipologia Proposta para a Organização do Fluxo de Produtos

Uma vez apresentadas as decisões logísticas individuais relacionadas à 
organização do fluxo de produtos nas dimensões responsabilidade, espaço e tempo, cabe apresentar como estas três decisões poderiam ser combinadas em tipos para a organização do fluxo de produtos.

Neste sentido, é indicada no Quadro 1 uma tipologia para classificação da organização dos fluxos de produtos, a partir da combinação das três decisões logísticas discutidas na seção anterior. Teoricamente, existiriam oito diferentes tipos resultantes da combinação entre as duas alternativas de coordenação do fluxo de produtos (puxar e empurrar); as duas de alocação dos estoques (centralização e descentralização) e as duas da base para acionamento da fabricação (produção para estoque e produção contrapedido), pois 2 × 2 × $2=8$. Entretanto, destes oito possíveis tipos, apenas seis poderiam ocorrer na prática: Empurrar/Descentralizar/Para estoque, Empurrar/Centralizar/Para estoque, Puxar/ Descentralizar/Para estoque, Puxar/Descentralizar/Contrapedido, Puxar/ Centralizar/Para estoque e Puxar/Centralizar/Contrapedido. A explicação lógica é que a decisão de produzir contrapedido depende exclusivamente da reação à demanda real (puxar) e não de previsões de venda (empurrar). Esta restrição eliminaria as combinações Empurrar/Descentralizar/Contrapedido e Empurrar/ Centralizar/Contrapedido.

\section{Quadro 1: Tipos de Organização do Fluxo de Produtos}

\begin{tabular}{|l|l|l|}
\hline Coordenação & Alocação & Base para Acionamento \\
\hline Empurrar & Descentralizar & Para estoque \\
\hline Empurrar & Centralizar & Para estoque \\
\hline Puxar & Descentralizar & Para estoque \\
\hline Puxar & Descentralizar & Contrapedido \\
\hline Puxar & Centralizar & Para estoque \\
\hline Puxar & Centralizar & Contrapedido \\
\hline
\end{tabular}

A tipologia apresentada no Quadro 1 expande a proposta de Pagh e Cooper (1998) para a classificação da organização do fluxo de produtos, ao acrescentar a dimensão de coordenação (empurrar versus puxar). De acordo com os autores, existiriam quatro possíveis tipos de organização do fluxo de produtos acabados: Descentralizar/Para estoque, Descentralizar/Contrapedido, Centralizar/Para estoque e Centralizar/Contrapedido.

Até o presente momento, a literatura não reporta pesquisas que tenham buscado determinar quais características do negócio afetariam a escolha de determinado tipo de organização do fluxo de produtos. Artigos com relatos de evidências empíricas e justificativas para tal escolha também são escassos. Seria relevante entender quais características do negócio afetariam a escolha de determinado 
tipo de organização do fluxo, pois: (1) complementaria a avaliação do nível transversal, na medida em que as três decisões são consideradas em conjunto; e (2) estabeleceria as bases para a segmentação de eventual estratégia logística, a partir das características do negócio.

\section{Objetivos e Metodologia da Pesquisa}

Tomando como ponto de partida o referencial teórico e considerando a perspectiva de uma empresa fabricante de bens de consumo, a pergunta principal a ser respondida por meio da pesquisa de campo sobre o nível transversal da criação de posições competitivas na logística é:

\section{Quais são as características do produto, da operação e da demanda significativamente correlacionadas com as decisões logísticas individuais e com os tipos de organização do fluxo de produtos?}

Mais especificamente, e para fins de orientação da pesquisa, esta pergunta geral se desdobra nas seguintes perguntas específicas, passíveis de falseamento, a partir de testes de hipóteses ${ }^{(7)}$.

. Quais são as características do produto, da operação e da demanda significativamente correlacionadas com as decisões individuais de (1) coordenação do fluxo de produtos, (2) alocação dos estoques e (3) base para acionamento da fabricação de produtos acabados?

- Quais são as características do produto, da operação e da demanda significativamente correlacionadas com os tipos de organização do fluxo de produtos: Empurrar/Descentralizar/Para estoque, Empurrar/Centralizar/Para estoque, Puxar/Descentralizar/Para estoque, Puxar/Descentralizar/ Contrapedido, Puxar/Centralizar/Para estoque e Puxar/Centralizar/ Contrapedido?

A resposta a estas questões permitirá a proposição de quadros conceituais de apoio à tomada de decisão com relação às decisões logísticas individuais e com relação aos tipos de organização do fluxo de produtos. Estes quadros refletiriam a lógica e o referencial teórico que sustentam a avaliação transversal, permitindo identificar o padrão decisório mais aderente a determinado conjunto de características do negócio.

A população considerada como ponto de partida para a pesquisa de campo é 
definida pelo conjunto das 500 empresas que compõem a lista da publicação Exame Melhores e Maiores Edição 2000. A população em estudo é composta por 22 diferentes setores da economia (subpopulações), abrangendo atividades de cunho extrativo, industrial e de serviços. Em função da delimitação da pesquisa aos reconhecidos setores industriais de bens de consumo duráveis e nãoduráveis que vendem necessariamente, mas não exclusivamente, para o varejo, foram descartadas as subpopulações relacionadas ao setor primário e terciário da economia, além das subpopulações do setor secundário não enquadradas nesta restrição.

As subpopulações (tamanhos) analisadas na pesquisa de campo são as dos setores Químico e Petroquímico (46), Alimentício (40), Automotivo (31), Tecnologia e Computação (26), Eletro-eletrônico (21) e Farmacêutico (17). O tamanho total destas subpopulações perfaz 181 empresas, ou 36,2\% da população total de 500 empresas. Entretanto, se for considerado para efeito de definição populacional o conjunto de setores industriais de bens de consumo duráveis e nãoduráveis que vendem necessariamente, mas não exclusivamente, para o varejo, o tamanho da população é de 254 empresas. As seis subpopulações analisadas pela pesquisa perfazem $71,3 \%$ deste total.

Para cada uma destas seis subpopulações foram coletadas seis amostras, obedecendo a um processo quase-aleatório (quasi-random) com repetição. O processo foi quase-aleatório, porque, apesar da amostra de cada subpopulação ter sido gerada aleatoriamente, parte das empresas inicialmente contatadas recusou-se a participar da pesquisa de campo. Isto levou a sua substituição por outras da mesma subpopulação que se dispusessem a participar da pesquisa (amostragem por conveniência). O processo foi com repetição, porquanto de cada empresa foram coletadas informações referentes a um SKU classe A em faturamento e a um SKU classe C em faturamento. A determinação do tamanho amostral para cada subpopulação teve como base o entendimento e a interconexão dos seguintes aspectos do plano de pesquisa: a possibilidade de aproximação pela distribuição normal, a estratificação da amostra e a escolha do método estatístico. Foram considerados os aspectos assinalados a seguir.

. Não existe tamanho amostral mínimo necessário para confirmar a validade da aproximação pela distribuição normal em cada subpopulação, por dois motivos básicos: além de as subpopulações serem finitas e pequenas, alguns relatos indicam o caráter assimétrico de variáveis setoriais (ver, por exemplo, Cochran [1963]). 
- Como a estimação de parâmetros populacionais não é o objetivo principal da pesquisa, mas a identificação da correlação entre as variáveis (características e padrões de decisão), as frações amostrais de cada estrato não precisam ser necessariamente iguais à fração de cada subpopulação (estratificação proporcional). O tamanho amostral dos seis estratos pesquisados pode ser igual para efeitos de simplificação e de conveniência (estratificação desproporcional), segundo Moser e Kalton (1971) e Castro (1978).

- Os testes não-paramétricos não exigem que os tamanhos das amostras das seis subpopulações pesquisadas sejam iguais. Os testes não-paramétricos devem ser empregados quando não é válida a premissa da aproximação pela distribuição normal nas subpopulações (Conover, 1971).

Observados estes aspectos, optou-se inicialmente por amostras de tamanho igual a 5, em cada um dos seis setores. O quadro final com os tamanhos amostrais e as frações amostrais coletadas é apresentado na Tabela 1.

\section{Tabela 1: Tamanhos Amostrais e Frações Amostrais Coletadas nos Seis Setores Pesquisados}

\begin{tabular}{|l|l|l|l|}
\hline \multicolumn{1}{|c|}{ Subpopulações } & Tamanhos & $\begin{array}{c}\text { Tamanhos } \\
\text { Amostrais Finais }\end{array}$ & $\begin{array}{c}\text { Frações } \\
\text { Amostrais Finais }\end{array}$ \\
\hline Químico e Petroquímico & 46 & 5 & $10.9 \%$ \\
\hline Alimentício & 40 & 5 & $12.5 \%$ \\
\hline Automotivo & 31 & 3 & $9.7 \%$ \\
\hline Eletro-eletrônicos & 26 & 4 & $15.4 \%$ \\
\hline Tecnologia e Computação & 21 & 4 & $19.0 \%$ \\
\hline Farmacêutico & 17 & 5 & $29.4 \%$ \\
\hline Total & $\mathbf{1 8 1}$ & $\mathbf{2 6}$ & $\mathbf{1 4 . 4 \%}$ \\
\hline
\end{tabular}

As variáveis coletadas são apresentadas na Tabela 2. Esta tabela contém estatísticas descritivas (médias e desvios-padrões) para cada uma das características e das decisões incluídas na pesquisa. A Tabela 2 também apresenta a definição operacional de cada variável. 


\section{Tabela 2: Operacionalização e Estatísticas Descritivas das Variáveis Coletadas na Pesquisa de Campo}

\begin{tabular}{|l|l|l|l|}
\hline Características & Definição & Média & Desvio-padrão \\
\hline $\begin{array}{l}\text { Custo do Produto } \\
\text { Vendido }\end{array}$ & $\$ 21.458,26$ & $\$ 77.435,09$ \\
\hline Obsolescência & 1/ (Ciclo de vida do produto - em meses) & 0,03 & 0,05 \\
\hline Razão entre Prazos & $\begin{array}{l}\text { (Prazo de entrega do produto acabado para } \\
\text { o cliente - em dias)/ (Prazo de entrega da } \\
\text { matéria prima mais crítica pelo fornecedor } \\
\text { - em dias) }\end{array}$ & 0,16 & 0,33 \\
\hline $\begin{array}{l}\text { Visibilidade da } \\
\text { Demanda }\end{array}$ & $\begin{array}{l}\text { Se Sim, então }=1 \\
\text { Se Não, então }=0\end{array}$ & 0,23 & 0,43 \\
\hline Prazo de Entrega & $\begin{array}{l}\text { Prazo desde a colocação do pedido pelo } \\
\text { cliente até sua entrega - em dias }\end{array}$ & 5,34 & 11,26 \\
\hline $\begin{array}{l}\text { Densidade de } \\
\text { Custos (\$/kg) }\end{array}$ & (Custo do Produto Vendido)/(Peso em kg) & $\$ 1.889,89$ & $\$ 11.055,20$ \\
\hline $\begin{array}{l}\text { Coeficiente de } \\
\text { Variação nas } \\
\text { Vendas }\end{array}$ & $\begin{array}{l}\text { (Desvio-padrão das vendas)/ (Média das } \\
\text { vendas) }\end{array}$ & 0,4499 & 0,176 \\
\hline $\begin{array}{l}\text { Giro dos Estoques } \\
\text { (vezes/ano) }\end{array}$ & $\begin{array}{l}\text { (Vendas anuais }- \text { unidades) / (Estoque } \\
\text { médio }- \text { unidades) }\end{array}$ & 29,00 & 33,16 \\
\hline Decisões & Definição & Média & Desvio-padrão \\
\hline $\begin{array}{l}\text { Alocação dos } \\
\text { Estoques }\end{array}$ & $\begin{array}{l}\text { Se Descentralização }=1 \\
\text { Se Centralização }=0\end{array}$ & 0,62 & 0,49 \\
\hline $\begin{array}{l}\text { Base para } \\
\text { Acionamento da } \\
\text { Fabricação }\end{array}$ & $\begin{array}{l}\text { Se Para estoque }=1 \\
\text { Se Contrapedido }=0\end{array}$ & 0,77 & 0,43 \\
\hline $\begin{array}{l}\text { Coordenação do } \\
\text { Fluxo de Produtos }\end{array}$ & $\begin{array}{l}\text { Se Puxar }=1 \\
\text { Se Empurrar }=0\end{array}$ & 0,31 & 0,46 \\
\hline
\end{tabular}

\section{Análise e Discussão de Resultados}

As análises de correlação entre as características e as decisões indicaram um número considerável de resultados significativos a 0,05, corroborando parte das evidências relatadas na literatura. A partir destes resultados, foram desenvolvidos quadros conceituais para cada uma das decisões pesquisadas, sendo apresentadas as implicações para a tomada de decisão. Estes resultados são apresentados e discutidos separadamente para cada uma das decisões logísticas individuais e para os tipos de organização do fluxo de produtos.

\section{Coordenação do Fluxo de Produtos Acabados}

Esta decisão não apresentou correlações estatisticamente significativas a 0,05 com a visibilidade da demanda e o prazo de entrega, conforme apontado pela revisão da literatura. Outras características como a obsolescência, o custo do 
produto vendido e a razão entre prazos apresentaram correlações estatisticamente significativas com esta decisão, conforme apresentado na Tabela 3.

\section{Tabela 3: Correlações Significativas entre a Coordenação do Fluxo de Produtos e as Características do Negócio}

\begin{tabular}{|l|l|l|}
\hline \multicolumn{3}{|c|}{ Coordenação do Fluxo de Produtos Acabados (N = 52) } \\
Puxar = 1/ Empurrar = 0 \\
\hline Característica & Correlação & Significância \\
\hline Obsolescência & 0,496 & $<0,001$ \\
\hline Custo do Produto Vendido & 0,356 & 0,005 \\
\hline Razão entre Prazos & 0,307 & 0,016 \\
\hline
\end{tabular}

De acordo com a Tabela 3, a decisão de puxar o fluxo de produtos, ou seja, de reagir à demanda real, apresenta forte correlação com produtos de alto CPV, maior razão entre prazos e elevada obsolescência. Por outro lado, a decisão de empurrar o fluxo de produtos, ou seja, de planejar com base em previsões de venda, apresenta forte correlação com produtos de baixo CPV, menor razão entre prazos e baixa obsolescência.

Estes resultados são coerentes com evidências empíricas relatadas na literatura. Por exemplo, segundo Dell (1999), os principais motivadores para a estruturação do Modelo Direto na Dell Computers foram o curto ciclo de vida dos produtos e seus componentes, o elevado custo de oportunidade de manter estoques, o fato de os seus clientes aceitarem maiores prazos de entrega para receberem produtos personalizados mais condizentes com as suas necessidades e com a integração, por meio da Internet, do processo produtivo com seus fornecedores.

O cálculo das estatísticas descritivas para cada uma destas características seria extremamente relevante para quantificar sob quais circunstâncias deveria ser puxado ou empurrado o fluxo de produtos. As estatísticas descritivas poderiam auxiliar a tomada de decisão sobre a coordenação do fluxo de produtos. Seria possível responder às seguintes questões: qual é a magnitude típica de um alto CPV? A partir de qual patamar pode um produto ser considerado de baixa obsolescência? Qual é a ordem de grandeza de uma elevada razão entre prazos?

A Tabela 4 constitui um quadro conceitual de apoio à tomada de decisão, apresentando a mediana das características significativamente correlacionadas com a decisão de coordenação do fluxo de produtos. Segundo esta tabela, produtos com CPV inferior a \$ 6,50, sem obsolescência e com razão entre prazos inferior a 0,03 deveriam ser empurrados. Por outro lado, deveriam ser puxados produtos 
com CPV superior a \$ 680, com obsolescência superior a 0,04 (equivalente a um ciclo de vida de 25 meses) e com razão entre prazos superior a 0,11.

Tabela 4: Quadro Conceitual de Apoio à Decisão sobre a Coordenação do Fluxo de Produtos

\begin{tabular}{|l|l|l|l|}
\hline Medianas & CPV & Obsolescência & Razão entre Prazos \\
\hline Empurrar & $\$ 6,50$ & 0,00 & 0,03 \\
\hline Puxar & $\$ 680,00$ & 0,04 & 0,11 \\
\hline
\end{tabular}

\section{Alocação dos Estoques de Produtos Acabados}

Esta decisão apresentou correlações estatisticamente significativas com a densidade de custos, o coeficiente de variação nas vendas e o giro dos estoques, conforme se indica na Tabela 5. Variáveis como o CPV e a obsolescência, ao contrário do que apontava a revisão da literatura, não apresentaram correlações significativas a 0,05 .

Tabela 5: Correlações Significativas entre a Alocação dos Estoques de Produto Acabado e as Características do Negócio

\begin{tabular}{|l|l|l|}
\hline \multicolumn{4}{|c|}{$\begin{array}{c}\text { Alocação dos Estoques de Produtos Acabados (N = 52) } \\
\text { Descentralizar }=\mathbf{1} \text { / Centralizar }=\mathbf{~ 0 ~}\end{array}$} \\
\hline Característica & Correlação & Significância \\
\hline Densidade de Custos & $-0,351$ & 0,008 \\
\hline Coeficiente de Variação nas Vendas & $-0,295$ & 0,027 \\
\hline Giro dos Estoques & 0,274 & 0,031 \\
\hline
\end{tabular}

De acordo com a Tabela 5, a decisão de descentralizar os estoques apresenta forte correlação com produtos de baixa densidade de custos, baixo coeficiente de variação nas vendas e elevado giro nos estoques. Por outro lado, a decisão de centralizar os estoques apresenta forte correlação com produtos de alta densidade de custos, alto coeficiente de variação nas vendas e pequeno giro nos estoques. Estes resultados apontam que a decisão de alocação dos estoques é influenciada por características que refletem os riscos associados à manutenção dos estoques (giro e coeficiente de variação nas vendas) e a necessidade de explorar economias de escala na distribuição (densidade de custos).

Na Tabela 6 são apresentadas as medianas das características significativamente correlacionadas com a decisão de alocação dos estoques. Esta tabela também constitui um quadro conceitual de apoio à decisão sobre a alocação dos produtos, 
permitindo responder a questões como: qual é a magnitude típica de um produto com elevado giro? A partir de qual patamar pode um produto ser considerado de baixa densidade de custos? Qual é a ordem de grandeza de um elevado coeficiente de variação nas vendas?

Tabela 6: Quadro Conceitual de Apoio à Decisão sobre a Alocação dos Estoques

\begin{tabular}{|l|l|l|l|}
\hline Medianas & $\begin{array}{c}\text { Densidade de } \\
\text { Custos }\end{array}$ & $\begin{array}{c}\text { Coeficiente de Variação } \\
\text { nas Vendas }\end{array}$ & \multicolumn{1}{|c|}{$\begin{array}{c}\text { Giro dos } \\
\text { Estoques }\end{array}$} \\
\hline Centralizar & $\$ 40,17$ & 2,50 & 12,00 \\
\hline Descentralizar & $\$ 3,21$ & 1,33 & 24,00 \\
\hline
\end{tabular}

\section{Base para Acionamento da Fabricação de Produtos Acabados}

De acordo com a literatura, esta decisão apresentou correlações significativas com o CPV, a obsolescência e a razão entre prazos (vide Tabela 7). Estas três características são as mesmas que afetam a decisão de coordenação do fluxo de produtos acabados. Não obstante, estas duas decisões são fortemente correlacionadas $(-0,822 ;<0,001)$, o que é explicado pelo fato de os fluxos de produtos empurrados dependerem necessariamente de previsão de vendas, ao passo que os fluxos de produtos puxados são, na sua maioria, uma resposta à demanda real.

Tabela 7: Correlações Significativas entre a Base para Acionamento da Fabricação de Produtos Acabados e as Características do Negócio

\begin{tabular}{|l|l|l|}
\hline \multicolumn{3}{|c|}{$\begin{array}{c}\text { Base para Acionamento da Fabricação de Produtos Acabados } \\
\text { Para Estoque = 1/ Contrapedido }=\mathbf{0}\end{array}$} \\
\hline Característica & Correlação & Significância \\
\hline Obsolescência & $-0,491$ & $<0,001$ \\
\hline Custo do Produto Vendido & $-0,411$ & 0,001 \\
\hline Razão entre Prazos & $-0,312$ & 0,014 \\
\hline
\end{tabular}

De acordo com a Tabela 7, a decisão de produzir para estoque apresenta forte correlação com produtos de baixo CPV, pequena razão entre prazos e baixa obsolescência. Por outro lado, a decisão de produzir contrapedido apresenta forte correlação com produtos de alto CPV, elevada razão entre prazos e alta obsolescência. Estes resultados apontam que a decisão de base para acionamento é influenciada por características que refletem os riscos e os custos associados à 
manutenção dos estoques (obsolescência e custo do produto vendido) e a necessidade de resposta rápida aos clientes (razão entre prazos). Na Tabela 8 são apresentadas as medianas das variáveis significativamente relevantes para a definição da base de acionamento. Esta tabela também constitui um quadro conceitual de apoio à decisão.

\section{Tabela 8: Quadro Conceitual de Apoio à Decisão sobre a Base de Acionamento da Fabricação de Produtos Acabados}

\begin{tabular}{|l|l|l|l|}
\hline Medianas & CPV & Obsolescência & Razão entre Prazos \\
\hline Contrapedido & $\$ 8.000,00$ & 0,04 & 0,11 \\
\hline Para estoque & $\$ 6,50$ & 0,00 & 0,03 \\
\hline
\end{tabular}

\section{Tipos de Organização do Fluxo de Produtos}

Os resultados das análises de correlação sugerem que diferentes combinações de características do negócio influenciam a adoção de determinado tipo de organização do fluxo de produtos. Sua adoção parece não estar associada a um único conjunto homogêneo de características. Estes conjuntos heterogêneos de características poderiam ser a chave para a segmentação de eventual estratégia logística. A segmentação teria por base a escolha do tipo de organização do fluxo de produtos mais adequado às características em exame.

O tipo Empurrar/Descentralizar/Para estoque apresentou-se estatisticamente correlacionado com o coeficiente de variação nas vendas $(-0,306 ;<0,05)$ e com a razão entre prazos $(-0,268 ;<0,05)$. O sinal destas correlações indica que este tipo de organização do fluxo de produtos está relacionado a produtos com baixo coeficiente de variação nas vendas e pequena razão entre prazos.

O tipo Puxar/Descentralizar/Para estoque não apresentou correlação significativa com quaisquer das características do negócio. O tipo Empurrar/ Centralizar/Para estoque apresentou-se estatisticamente correlacionado com a obsolescência $(-0,305 ;<0,05)$ e com o giro dos estoques $(-0,242 ;<0,05)$. O sinal destas correlações indica que o tipo Empurrar/Centralizar/Para estoque está relacionado a produtos com longo ciclo de vida (pequena obsolescência) e com baixo giro dos estoques.

O tipo Puxar/Centralizar/Para estoque é estatisticamente correlacionado com o custo do produto vendido $(0,844 ;<0,01)$ e com a obsolescência $(0,276 ;<0,05)$. O sinal destas correlações indica que este tipo de organização do fluxo de produtos está relacionado a produtos com alto custo do produto vendido e alta obsolescência. 
O tipo Puxar/Descentralizar/Contrapedido é estatisticamente correlacionado com o coeficiente de variação nas vendas $\left(0,341^{* *} ;<0,05\right)$ e o giro dos estoques $(0,263 ;<0,05)$. O sinal destas correlações indica que a adoção do tipo Puxar/ Descentralizar/Contrapedido está relacionada a produtos com alto coeficiente de variação nas vendas e elevado giro dos estoques.

Finalmente, o tipo Puxar/Centralizar/Contrapedidoé estatisticamente correlacionado com a obsolescência $(0,383 ;<0,05)$ e a razão entre prazos $\left(0,343^{* *} ; 0,05\right)$. O sinal destas correlações indica que a adoção deste tipo de organização do fluxo de produtos está relacionada a produtos com elevada obsolescência e elevada razão entre prazos.

A ilustração a seguir constitui um quadro conceitual de apoio à tomada de decisão, indicando quais e como (sinais) as características do negócio favoreceriam determinado tipo de organização do fluxo de produtos nas dimensões responsabilidade, espaço e tempo.

\section{Quadro 2: Correlações Significativas entre os Tipos de Organização do Fluxo de Produtos e as Características do Negócio}

\begin{tabular}{|l|l|l|l|l|l|l|}
\hline Tipos de Organização do Fluxo de Produtos & $\mathrm{O}$ & $\mathrm{CPV}$ & $\mathrm{RP}$ & $\mathrm{DC}$ & $\mathrm{CV}$ & $\mathrm{G}$ \\
\hline Empurrar/Descentralizar/Para estoque & & & $(-)$ & & $(-)$ & \\
\hline Puxar/Descentralizar/Para estoque & & & & & & \\
\hline Empurrar/Centralizar/Para estoque & $(-)$ & & & & & $(-)$ \\
\hline Puxar/Centralizar/Para estoque & $(+)$ & $(+)$ & & & & \\
\hline Puxar/Descentralizar/Contrapedido & & & & & $(+)$ & $(+)$ \\
\hline Puxar/Centralizar/Contrapedido & $(+)$ & & $(+)$ & & & \\
\hline
\end{tabular}

\section{Conclusões}

A partir deste estudo exploratório foi possível estabelecer diversos quadros conceituais de apoio à decisão, em função das características do negócio, para dois níveis distintos. O primeiro refere-se às decisões logísticas individuais, que permitem a caracterização do fluxo de produtos nas suas dimensões principais (responsabilidade, espaço e tempo). O segundo refere-se à combinação destas decisões em seis tipos de organização do fluxo de produtos, que poderiam constituir a base para a segmentação de eventual estratégia logística.

Com base nas análises de correlação possibilitou-se o que se assinala a seguir.

- Corroborar parte dos sinais das relações das características do negócio com as decisões individuais, conforme revisão de literatura, além de identificar outras relações relevantes no ambiente de negócio brasileiro. 
. Identificar que a decisão de coordenação do fluxo de produtos é influenciada pela obsolescência, pela razão entre prazos e pelo custo do produto vendido.

- Identificar que a decisão de alocação dos estoques é influenciada pela densidade de custos, pelo coeficiente de variação nas vendas e pelo giro do produto.

- Confirmar a forte correlação teórica entre as decisões de coordenação do fluxo de produtos e a base para acionamento da fabricação.

- Identificar que os tipos de organização do fluxo de produtos não estão relacionados a um conjunto homogêneo de características do negócio.

Em síntese, estes quadros de apoio à decisão revelam a importância das características do produto, da operação e da demanda para a avaliação do nível transversal na logística. Os quadros também proporcionam a base para a interpretação de diferentes aspectos relacionados ao fenômeno em estudo. No entanto eles deixam aberta uma série de questões relevantes para a compreensão da evolução do fluxo de produtos ao longo do tempo (avaliação do nível longitudinal), tópico que deve ser objeto de pesquisas futuras.

\section{Notas}

${ }^{1}$ Indica se a empresa acessa ou não a demanda do consumidor final (demanda real da cadeia).

${ }^{2}$ Na realidade, a literatura especializada faz referência aos custos adicionados do produto. O custo do produto vendido é utilizado neste manuscrito como aproximação aos custos adicionados do produto.

${ }^{3}$ Razão entre o custo do produto vendido e o peso ou volume do produto, visando a responder quanto custaria o produto por kg ou m3.

${ }^{4}$ Inverso da duração do ciclo de vida do produto; produtos com ciclos de vida mais longos apresentariam maior obsolescência.

5 Razão entre o desvio-padrão e a média das vendas.

6 Cociente entre o prazo de entrega do produto acabado para o cliente e o prazo de entrega da matéria prima pelo fornecedor. Quanto maior esta razão, mais flexível e de menor custo poderia ser a capacidade de resposta da empresa para o cliente, em função da possibilidade de centralizar os estoques e produzir contrapedido.

7 Convencionalmente, os testes de hipótese testam a congruência teoria-fato na direção de os dados empíricos validarem a teoria (Castro, 1978). Um exemplo neste sentido seria a centralização dos estoques de produtos com alto custo adicionado (fato). A justificativa teórica para tal decisão seria o benefício obtido com a redução dos níveis de estoque de segurança na rede logística e a conseqüente desmobilização de capital de giro empatado. Caso se verifique uma correlação significativa (teste de hipótese) entre as variáveis custo adicionado (independente ou explicativa) e centralização dos estoques (dependente), poder-se-ia deduzir, com base no arcabouço teórico, que esta decisão se relaciona com o desejo de reduzir os custos de oportunidade de manter estoques. 
ReferênCIAs Bibliográficas

ABAD, P. L.

Optimal pricing and lot-sizing under conditions of perishability, finite production and partial backordering and lost sale. European Journal of Operations Research, v. 144, n. 3, p. 677-686, 2003.

BALLOU, R. H.

Business logistics management. Englewood Cliffs, NJ: Prentice Hall, 1992.

BALLOU, R. H.;

GILBERT, S. M.

New managerial challenges from supply chain opportunities. Industrial Marketing Management, v. 29, p. 7-18, 2000.

BOWERSOX, D. J.;

CLOSS, D. J.

Logistical management: the integrated supply chain process. New York: McGraw-Hill, 1996.

CASTRO, C. M.

A prática da pesquisa. São Paulo: McGraw-Hill, 1978.

CHRISTOPHER, M.

Logística e gerenciamento da cadeia de suprimentos: estratégias para redução de custos e melhoria dos serviços. São Paulo: Pioneira, 1997.
The agile supply chain: competing in volatile markets. Industrial Marketing Management, v. 29, p. 37-44, 2000.

CLOSS, D. J.;

ROATH, A. S.

An empirical comparison of anticipatory and response based supply chain strategies.

International Journal of Logistics Management, v. 9, n. 2, p. 21-34, 1998.

COCHRAN, W. G.

Sampling techniques. New York: John Wiley \& Sons, 1963.

CONOVER, W. J.

Practical nonparametric statistics. New York: John Wiley \& Sons, 1971.

COUNCIL OF LOGISTICS MANAGEMENT.

Disponível em <http:// www.clml.org > . Acesso em: 20-

DELL, M.

Direct from Dell. New York: Harperbusiness, 1999.

INMAN, R.

Are you implementing a pull system by putting the cart before the horse? Production and Inventory Management Journal, v. 40, n. 2, p. 67-71, 1999. 
JAYARAMAN, V.

Transportation, facility location and inventory issues in distribution network design. International Journal of Operations \& Production Management, v. 18, n. 5, p. 471-494, 1998.

LAMBERT, D. M.;

COOPER, M.;

PAGH, J.

Supply chain management: implementation issues and research opportunities. The International Journal of Logistics Management, v. 9, n. 2, p. 1-20, 1998.

LEEUW, S. D.;

GOOR, A. R.

The selection of distribution control techniques. The International Journal of Logistics Management, v. 10, n. 1, p. 97112, 1999.

MENTZER, J.;

KAHN, K.;

BIENSTOCK, C. C.

Sales forecasting executive study. London: Sage Publications, 1998.

MOSER, C.; KALTON, G.

Survey methods in social investigation. London: Heinemann, 1971.
PAGH, J.;

COOPER, M.

Supply chain postponement and speculation strategies: how to choose the right strategy. Journal of Business Logistics, v. 19, n. 2, p. 13-33, 1998.

PORTER, M.

Towards a dynamic theory of strategy. Strategic Management Journal, v. 12, p. 95-117, 1991.

ROMERO, B.

P. The other side of supply management. Production and Inventory Management Journal, v. 32, n. 4, p. 1-4, 1991.

SHARMAN, G.

The rediscovery of logistics. Harvard Business Review, p. 71-80, Sept./Oct. 1984.

SILVER, E. A.;

PETERSON, R.

Decision systems for inventory management and production planning. New York: John Wiley \& Sons, 1985.

STALK, G.

Time: the next source of competitive advantage. Harvard Business Review, p. 41-51, July/ Aug. 1988.

WATERS, C. D. J.

Inventory control and management. New York: John Wiley \& Sons, 1992. 